\title{
An Ultrahighly Sensitive Electrochemical Biosensor for Cytochrome c with Surface Molecular Imprinting Based on Hybrid Nanomaterials
}

\author{
Qin Wang ${ }^{1,2}$, Hao Guo ${ }^{1}$, Yuli Wei ${ }^{3}$, Rui Xue ${ }^{3}$, Baolong Ma ${ }^{1}$, Wu Yang ${ }^{1, *}$ \\ ${ }^{1}$ College of Chemistry and Chemical Engineering, Key Lab of Bioelectrochemistry and Environmental \\ Analysis of Gansu Province, Northwest Normal University, Lanzhou 730070, PR China \\ ${ }^{2}$ Zhonghao North Paint and Coatings Industry Research Institute Co., Ltd, Lanzhou 730020, PR China \\ ${ }^{3}$ College of Chemistry and Chemical Engineering, Lanzhou City University, Provincical Key \\ Laboratory of Gansu Higher Education for City Environmental Pollution Control, Lanzhou City \\ University, Lanzhou730070, P R China \\ *E-mail: xbsfda123@126.com
}

doi: $10.20964 / 2020.01 .25$

Received: 6 August 2019/ Accepted: 12 October 2019 / Published: 30 November 2019

\begin{abstract}
A novel ultrahighly sensitive 3D structural electrochemical imprinted biomacromolecular sensor for Cyt c was fabricated based on hybrid polyaniline nanotube/carboxylated multi-walled carbon nanotubes (PANTs-MWCNTs) composites by surface molecular imprinting method on the surface of glassy carbon electrode (GCE). The hybrid nanomaterials can enhance imprinting efficiency. The fabrication and electrochemical behavior of the prepared imprinted biosensor were studied by electrochemical techniques, scanning electron microscopy (SEM) and Fourier transform infrared spectra (FTIR). Under the optimal conditions, the detection of Cyt $\mathrm{c}$ with the imprinted sensor exhibited a wide linear range from $1.0 \times 10^{-14}$ to $1.0 \times 10^{-6} \mathrm{mg} / \mathrm{mL}$ with lower detection limit of $7.62 \times 10^{-16} \mathrm{mg} / \mathrm{mL}$. The developed procedure has been successfully used in assay of Cyt $\mathrm{c}$ in real samples.
\end{abstract}

Keywords: Cytochrome c; Electrochemical imprinted biosensor; Nanomaterials; Self-assembly.

\section{$\underline{\text { FULL TEXT }}$}

(C) 2020 The Authors. Published by ESG (www.electrochemsci.org). This article is an open access article distributed under the terms and conditions of the Creative Commons Attribution license (http://creativecommons.org/licenses/by/4.0/). 